\title{
Street Design and Urban Microclimate: Analyzing the Effects of Street Geometry and Orientation on Airflow and Solar Access in Urban Canyons
}

\author{
Nastaran Shishegar
}

\begin{abstract}
Urban climate is an effective issue on the local and global climates which is influenced by several factors such urban morphology and density, the properties of urban surfaces and vegetation cover. The inappropriate using of these factors could change the microclimate of urban areas. Streets as considerable parts of urban open spaces have a significant role in creating the urban microclimates. As street geometry and orientation influence the amount of solar radiation received by street surfaces and also airflow in urban canyons. This paper discusses the current literature and evidence for the effects of street design on the urban microclimate with highlighting the impacts of streets geometry $(\mathrm{H} / \mathrm{W}$ ratio) and orientation on airflow and solar access in an urban canyon. Researches conducted on this term have proved that street's geometry and orientation are key factors in providing a pleasant microclimate at pedestrian level in an urban canyon.
\end{abstract}

Index Terms-Urban microclimate, street's geometry and orientation, airflow, solar access

\section{INTRODUCTION}

Cites are responsive to urban climate instability and inconstancy and able to change their own climates. Urban climate is a critical factor which affects regional and global climates and consequently urban livability [1]-[3]. The microclimate of urban open spaces is influenced by several parameters such as the urban form and geometry, urban density, the vegetation, the water levels and the properties of surfaces. The inappropriate implementation of above-mentioned parameters contribute to the harshness of the environment and therefore, make the temperature in the urban areas higher than in the suburbs. This phenomenon called the urban heat island (UHI) [4]. The main reasons of forming UHI include heat trapping by urban geometry, properties of urban surfaces, replacement of vegetation by expansively built surfaces cover and the anthropogenic heat sources [5]-[7].

As more than a quarter of the urban areas are usually covered by streets, designing urban streets plays an important role in creating the urban climate. The urban streets vary in geometry as defined by height/width ratio $(\mathrm{H} / \mathrm{W})$ and length/width (L/W) and also the orientation that is defined by its long axis. These parameters directly influence the absorption and emission of solar radiation and also urban ventilation which have a significant impact on the

Manuscript received October 15, 2012; revised January 7, 2012.

Nastaran Shishegar is with factually of architecture and urban design, Iran University of Science and Technology (IUST), Tehran, Iran (email: nastaran.shishegar85@yahoo.com). temperature variations within the street as well as the surrounding environment (UHI) [8].

This paper reviews the current literature and evidence for the impacts of street design on the urban microclimate with especial focus on the effects of streets geometry (height/width ratio) and orientation on airflow and solar access in an urban street canyon.

\section{Street Canyon Design and URban Microclimate}

A street canyon refers to the space which is formed by two typically parallel rows of buildings separated by a street and it creates the basic unit of modern cities [9]. The geometry of a street canyon are expressed by its 'aspect ratio' including the ratio of the height of the building $(\mathrm{H})$ to width of the street (W). If the canyon has an aspect ratio of around equal to 1 with no major openings on the walls it is called a uniform street canyon. A canyon with an aspect ratio below 0.5 is a shallow street canyon; and the aspect ratio of 2 , represents a deep street canyon. The length of canyon (L) illustrates the road distance between two main intersections subdividing the street canyon into short $(\mathrm{L} / \mathrm{H}=3)$, medium $(\mathrm{L} / \mathrm{H}=5)$ and long $(\mathrm{L} / \mathrm{H}=7)[10]$.

It has been proved that the geometry and orientation of the street canyon affect outdoor and indoor environments, solar access inside and outside the buildings, the permeability to airflow for urban ventilation, as well as the potential for cooling of the whole urban system [11]. Therefore, the street design influences the thermal comfort at pedestrian level as well as the global energy consumption of urban buildings.

From a climatic point of view, in designing a street, the main complexity faced by the designer is the difference in the seasonal internal and external desires. For instance, in summer protection from the sun and in winter solar access are required. In theory, these imply compactness and openness to the sky, respectively [11].

According to the most related studies, street canyon geometry's parameters (height-to-width ratio $(\mathrm{H} / \mathrm{W})$ ) and the street orientation are the most relevant urban parameters responsible for the microclimatic changes in a street canyon [12]-[14]. These parameters directly affect the potential of airflow at street level, solar access and therefore urban microclimate $[14,15]$.

Although, traditional and contemporary architectures make a lot efforts to design urban streets according to climate, quantitative information about the best possible street design, based on scientific methods, in order to regulate the climate comfort is still required [16]-[17]. 


\section{IMPACTS OF STREET DESIGN ON AiRflow}

Urban airflow patterns are determined by the interaction between an approaching wind with the built environment. The formation of airflow within a street canyon is essential for human health, outdoor and indoor thermal comfort, air quality, the energy efficiency of buildings and thus, providing a pleasant urban microclimate [18, 19]. For instance, the cooling effect of airflow, particularly at night, could mitigate effects of urban heat island phenomenon. Several studies indicate that the pattern of an existing regional wind is changed when it flows through a built environment [20].Therefore, designing built environment and especially street canyon is a key factor in formation of urban airflow patterns.

The air over urban areas could be divided into main layers: urban canopy layer and urban boundary layer. The urban canopy layer is the layer blow roof tops in the spaces between buildings and influenced by solar energy falling on building facades and ground. The urban boundary layer is above the average height of buildings. Heat transfer, pollutant emission, evaporation and transpiration and generally contemporary urban development are the main factors affect air temperature in urban boundary layer [21].

Due to barriers such as buildings and trees, airflow in the urban canopy layer is more blocked in comparison with airflow in the urban boundary layer. Therefore, there is slower airflow in the urban canopy layer than in surrounding rural areas [22]. A secondary circulation feature driven by urban boundary layer provides airflow in an urban canyon which is strongly affected by the street orientation and geometry $(\mathrm{H} / \mathrm{W}$ and $\mathrm{L} / \mathrm{W})[15,23]$. When the airflow in the urban boundary layer is approximately normal to street axis, three airflow regimes with different characteristics could occur based on the aspect ratio $(\mathrm{H} / \mathrm{W})$ and building ratio (L/W) [22, 24] (Fig. 1: a): (a) the isolated roughness regime; (b) the wake interference regime; and (c) the skimming regime. The conversion from one regime to another happens at critical combinations of $\mathrm{H} / \mathrm{W}$ and L/W [25]-[26] (Fig. 1: b).

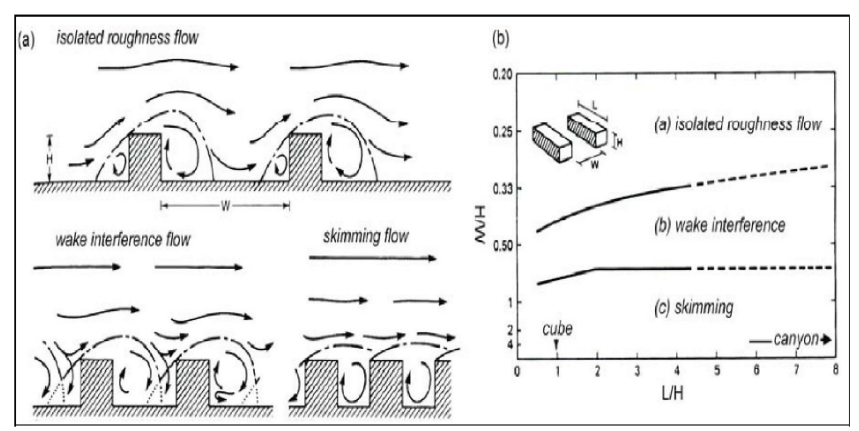

Fig. 1. Airflow regimes over an array of barriers the main flow features associated with each $[4,17,19]$.

The isolated roughness regime takes place between well spaced buildings, when there is no interaction between windward and leeward flows, similarly to a wind movement around an isolated barrier. By increasing the $\mathrm{H} / \mathrm{W}$ ratio, the wakes are disturbed leading to a wake interference regime. Further increase of $\mathrm{H} / \mathrm{W}$ ratio makes the street canyon isolated from the circulating air in the urban boundary layer and thus, a steady circulatory vortex is created in the canyon. This stable circulatory vortex brings about a skimming regime which is the most frequent in urban areas [13]. Therefore, it could be concluded that there is slower airflow in deep street canyons in comparison with uniform or shallow ones.

The impacts of street design on airflow have been investigated in many studies. For instance, Johansson [27] studied the influence of street geometry on airflow has been studied in Morocco as case studies with real site measurements for a period over 1.5 years. Both deep and shallow street canyons with aspect ratio of 9.7 and 0.6 respectively were studies in detail. The results illustrated an obvious relationship between street canyon geometry and the microclimate within an urban canyon $(1.7 \mathrm{~m})$. This study shows that the wind speeds are slower and more stable in the deep canyon $(0.4 \mathrm{~m} / \mathrm{s})$ in both winter and summer seasons. while the shallow street canyon had an average wind speed of $0.7 \mathrm{~m} / \mathrm{s}$ in summer and $0.8 \mathrm{~m} / \mathrm{s}$ in winter. In another study by Al-Sallal and Al-Rais [20] in Dubai, it has been proved that narrow street canyons (4 $\mathrm{m}$ and less) could increase wind speed passing through it, resulting in a better passive cooling performance yet creating eddies at bending angles. When the wind speed was higher $(5 \mathrm{~m} / \mathrm{s})$, wind reached deeper inside the traditional narrow streets providing better potential for thermal comfort. Most locations (49-57\% of the studied area) with street canyons aspect ratio of 2-0.67 had wind speeds that ranged from light to gentle breeze.

In addition, some studied assessed the impacts of building's heights on the airflow within a street canyon. In this term, Priyadarsini and Wong [28] found that strategically placing a few blocks of high-rise towers will improve the velocity within the street canyon when the airflow in parallel or perpendicular to the canyon. In addition, the temperature was lower when high-rise towers were placed in a street canyon. By placing some high rise towers, the velocity is increased by up to $90 \%$ for parallel flow and the temperature is decreased by up to $1^{\circ} \mathrm{C}$. For perpendicular flow, the velocity is increased up to 10 times and the temperature is decreased by $1.1^{\circ} \mathrm{C}$. Moreover, Robins and Macdonald [24] discovered that additional wakes creates additional air exchange and U-shaped vortices could occur by designing a few tall buildings among surrounding buildings restricted in the urban canopy layer (Fig. 2). Upstream tall buildings would bring about more vertical flow up from the street canyon to the urban boundary layer. Downstream buildings would create additional vertical flow down from the urban boundary layer into the urban canopy layer. In addition, providing adequate openings between streets and courts improves air exchange within the urban canopy layer.

Furthermore, it has been proved by Chan et al. [29] who discovered that better ventilation could be provided by different building heights. Therefore, tall buildings do not essentially promote obstacle. Moreover, they found out that better mixing of air is brought about by a wider urban canyon and street geometry should be limited to threshold value for skimming flow and the maximum relative canyon length ratio $\mathrm{L} / \mathrm{H}$ should not be more than five.

In addition to streets geometry and orientation, the configuration of street could affect the air flow at canopy 
layer. Streets which are straight and parallel to each other would promote air movement into and within the urban areas. Lack of vegetation and appropriate covers in straight streets causes severe heat (in hot-dry climate) or cold (in cold- dry climate) wind blow into the streets due to straight air movement [23] (Fig. 3). Narrow and winding streets reduce cold or hot winds and decrease the influence of stormy winds (Fig. 4). This pattern is proper for tow stressful climates (hot-dry and cold-dry) [23].

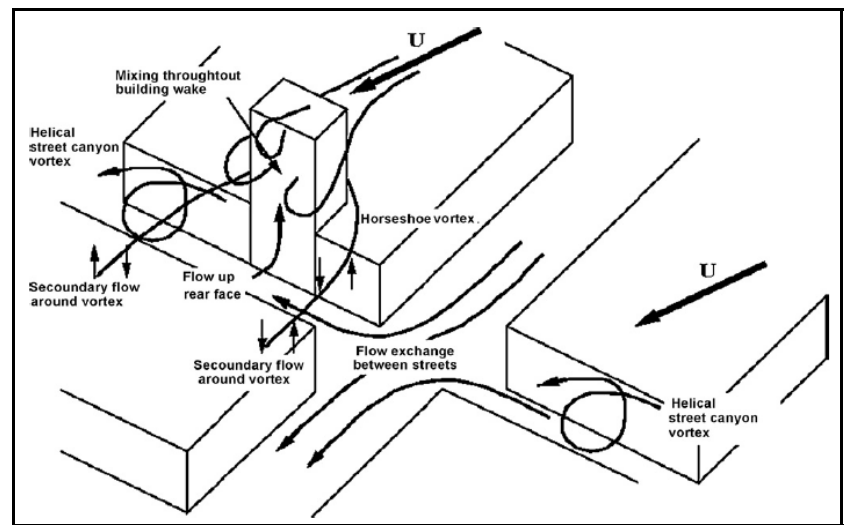

Fig. 2. Flow field at street intersection with a tall building indicating exchanges between the streets and additional mixing processes due to the large building $[17,19]$

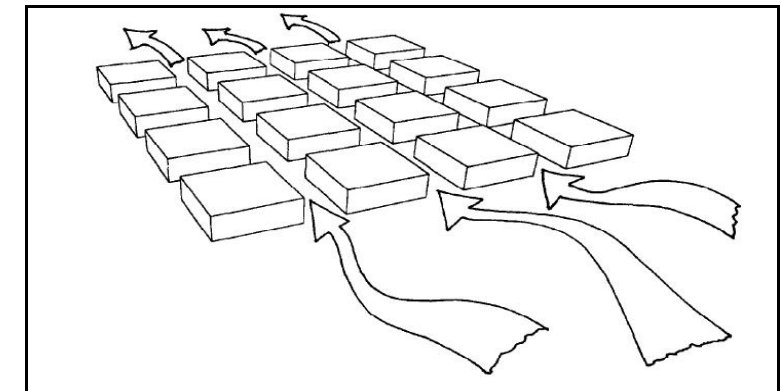

Fig. 3. Straight and parallel streets improve airflow into and within a city [23].

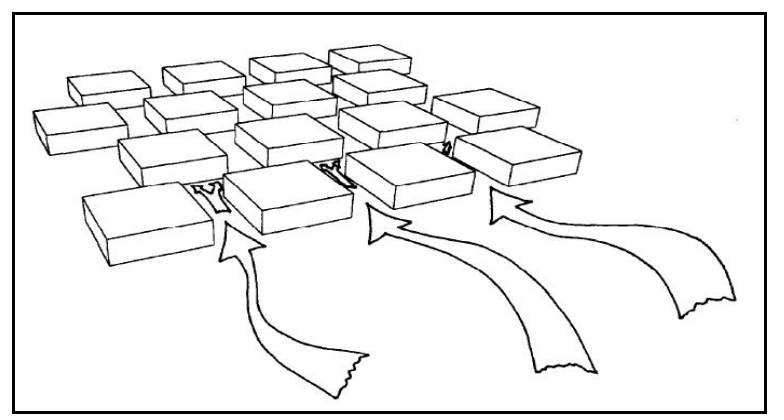

Fig. 4. Narrow and winding streets make airflow slow [23].

\section{IMPACTS OF STREet DESIGN ON SOlar ACCESS}

The impact of the sun on the climate is prominent. Solar energy falling on an urban area is received either by buildings facades and roofs or by the ground between buildings. From the urban street canyon point of view, the amount of solar radiation could directly influence the solar access and hence, thermal comfort at pedestrian level. Therefore, designing urban streets in a way which utilize solar access in urban canyon is vital to improve urban microclimate.

There are several studies which have evaluated the impacts of street's geometry and orientation on solar access within an urban canyon. Arnfield [7] investigated the amount solar access in different urban canyons by using a numerical method. The purpose of this study was to discover the dependence on aspect ratio and orientation of the irradiances on canyon facets (walls and floor) and on a pedestrian model. The research was conducted for E-W and N-S street's orientations for all latitudes and seasons. In addition, aspect ratios ranging was considered from 0.25 to 4 . Evaluating the monthly average irradiations illustrated that the $\mathrm{H} / \mathrm{W}$ ratio first influences the quantity of solar energy received by buildings and ground between buildings in a street canyon. By reducing the $\mathrm{H} / \mathrm{W}$ ratio the amount of solar energy received by the street surfaces increases (Fig. 5). However, this solar energy is not distributed equally on the various surfaces of the urban street. Fundamentally, the ground receives more solar radiation in comparison with vertical surfaces (walls). For a same street canyon the $\mathrm{H} / \mathrm{W}$ ratio influences the ground more than the walls.

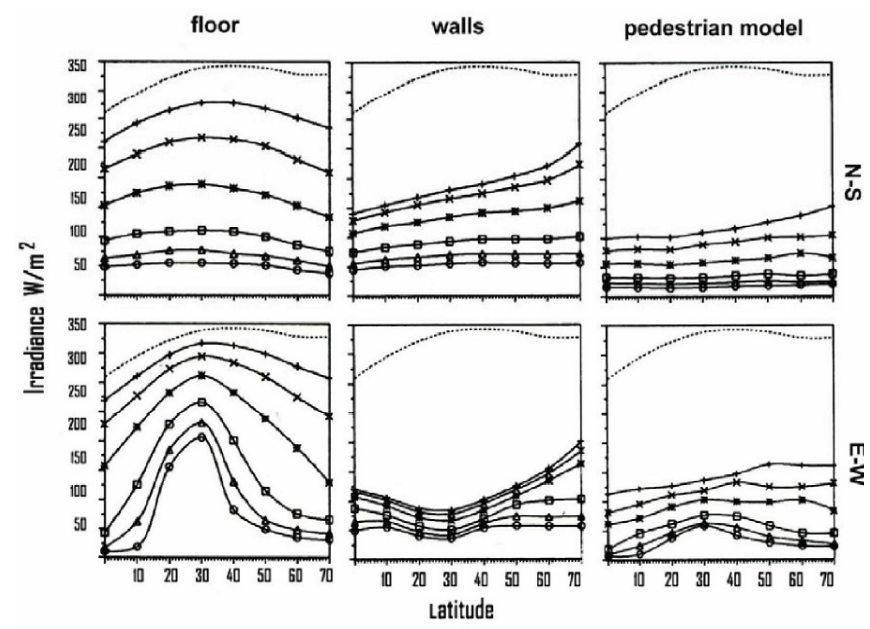

Fig. 5. Monthly mean canyon irradiances simulated for June for E-W and $\mathrm{N}-\mathrm{S}$ canyons and different aspect ratios. The symbols $+, \mathrm{x},{ }^{*}, \square, \Delta, \mathrm{O}$ correspond to $\mathrm{H} / \mathrm{W}=0.25,0.5,1,2,3$, and 4 respectively [7].

This study Arnfield [7] found out that the orientation of the street is more affective on the amount of solar energy obtained by walls and $\mathrm{H} / \mathrm{W}$ ratio influences the availability of solar energy on the ground. In addition, the impact of orientation is more significant in summer than in winter. There is an easier seasonal solar control for the buildings walls oriented N-S (i.e. E-W streets) as the walls are protected in the summer and exposed in the winter. For the pedestrian, the orientation hardly affects the irradiations. For higher latitudes, the sun position is lower in the winter and creates strong obstacles. Thus, the irradiances reduce for high latitudes and this is especially obvious for the E-W orientation. The effects of $\mathrm{H} / \mathrm{W}$ ratio and orientation of streets on receiving solar energy by ground and other street surfaces are more significant in latitudes $20^{\circ}-40^{\circ}$ in different seasons. This illustrates that in the subtropics climates, street geometry is more important for the solar control.

Former study has been proved by Van Esch et al [24] who analyzed the effects of street design parameters (width and orientation) on solar access to the urban canopy. They studied four street widths: 10, 15, 20 and $25 \mathrm{~m}$, with two orientation; E-W and N-S. All calculations and simulations are conducted with actual weather data for De Bilt, The Netherlands (52॰06_N and 5॰11_E) of the year 1995. 


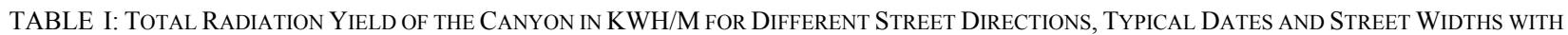
FLAT ROOFS [24].

\begin{tabular}{cccc}
\hline Street width $(\mathrm{m})$ & December 21st & March 21st & June 21st \\
\hline E-W street orientation & & & 124 \\
\hline 10 & 13.6 & 67.8 & 146 \\
15 & 16.0 & 78.6 & 169 \\
20 & 18.5 & 89.2 & 193 \\
25 & 21.0 & & 124 \\
\hline N-S street orientation & & 56.6 & 147 \\
10 & 13.8 & 66.8 & 170 \\
20 & 16.1 & 77.2 & 193 \\
\hline
\end{tabular}

Table I indicates the impact of increasing the street width. As shown, street width significantly affects the total global radiation yield of the canyon. For all studied canyon, increasing street width from $15 \mathrm{~m}$ to $20 \mathrm{~m}$ increases the radiation yield with $17-20 \%$. In different seasons the relative increase in radiation yield is more or less equal - about $19 \%$ per $5 \mathrm{~m}$ increase of the street width. However, the absolute increase differs quite strongly; as the radiation yield is rather low in winter; an extra $19 \%$ means only a few $\mathrm{kWh} / \mathrm{m}$, while in summer it is an extra $20-25 \mathrm{kWh} / \mathrm{m}$ [24].

Although street orientation hardly affects the total global radiation yield of the canyon, it brings about differences in the distribution of the total radiation yield over the different street surfaces - ground, facades and roof. Street orientation significantly influences the diurnal and seasonal pattern of irradiation of the street surfaces. Streets with an N-S orientation receive some solar radiation on the shortest day of the year (21st of December), even when the street is narrow (Fig. 6: a). Although this promotes thermal comfort in winter, spring and autumn, it could be unpleasant in summer, as there is no shade on the streets during the hottest day of the year. In contrast, streets with an E-W orientation are in shadow on the shortest day of the year, throughout the whole day, for all street widths studied (Fig. 6: b). In comparison with N-S oriented streets, streets with E-W orientation provide some shade during the hottest hours of the day. However, E-W oriented streets receive high percentages of direct solar radiation in the morning and afternoon in summer compared to N-S oriented streets [24].

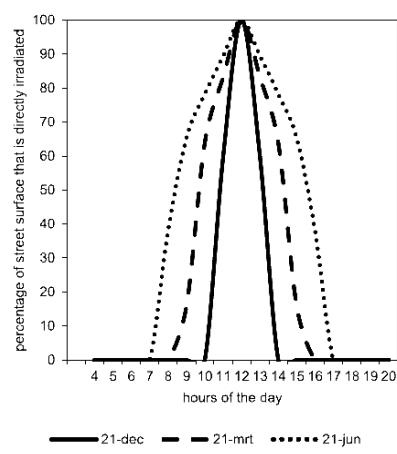

(a)

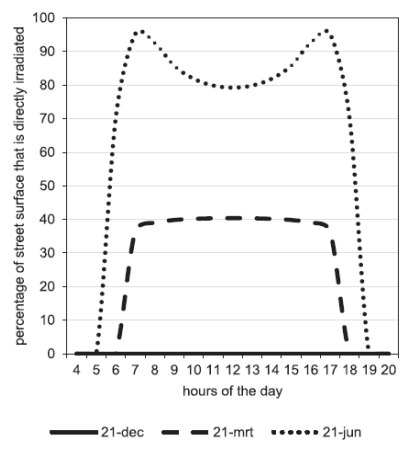

(b)
Fig. 6. Impacts of street orientation on solar access. Percentage of street surface that is directly irradiated when the street's orientation is N-S direction (a) and E-W (b) for the reference canyon (street width of $15 \mathrm{~m}$ ) [24].
On the other hand, in another study which is conducted in Ghardaia, Algeria, Ali-Toudert and Mayer [32] found out that for arid regions it is quiet difficult to keep an E-W oriented street canyon in the shade. In E-W orientation the walls provide very limited shading, even for very deep street canyons $(\mathrm{H} / \mathrm{W} \geq 2)$. In contrast, $\mathrm{N}-\mathrm{S}$ oriented street canyons create more pleasant microclimate as they provide enough shadow and solar energy in summer and winter respectively. Therefore, the orientation of the street canyon should be chose based on the area's latitude as in different latitude difernt orientation is appropriate.

On the other hand, in another study which is conducted in Ghardaia, Algeria, Ali-Toudert and Mayer [32] found out that for arid regions it is quiet difficult to keep an E-W oriented street canyon in the shade. In E-W orientation the walls provide very limited shading, even for very deep street canyons $(\mathrm{H} / \mathrm{W} \geq 2)$. In contrast, $\mathrm{N}-\mathrm{S}$ oriented street canyons create more pleasant microclimate as they provide enough shadow and solar energy in summer and winter respectively. Therefore, the orientation of the street canyon should be chose based on the area's latitude as in different latitude difernt orientation is appropriate.

In addition, Ali-Toudert and Mayer [32] concluded that better comfort conditions could be created by rotating the street to a NE-SW or NW-SE orientation. As in this case the shading effects of walls is more effective in summer compared to E-W oriented streets. Furthermore, in winter more solar access is provided by NE-SW or NW-SE oriented streets in comparison with N-S orientation. Nevertheless, a NE-SW orientation allows a solar exposure in the morning whereas NW-SE orientation implies an exposure of the walls in the afternoon, which could make the interior spaces overheated.

They also investigated the impacts of street orientation on solar access and found out that the availability of solar energy on the street's facades reduces rapidly with the increase of the aspect ratio of the canyon. These studies indicate that deep and narrow urban canyons $(\mathrm{H} / \mathrm{W} \geq 0.5)$ are more proper for hot regions as they reduce solar access generally. In contrast, uniform, shallow and generally wide street canyons $(\mathrm{H} / \mathrm{W} \leq$ $0.5)$ are appropriate for cold areas which require more solar access throughout the whole year. 


\section{CONCLUSION}

As streets covers around a quarter of urban areas, designing streets is a key issue in a global approach for an environmental urban design. The geometry of streets $(\mathrm{H} / \mathrm{W}$ and $\mathrm{L} / \mathrm{w}$ ratios) and orientation directly influence the airflow and solar access in urban canyon and therefore thermal comfort at pedestrian level. A wider street provides better mixing of air and consequently better airflow in the urban canyon. In addition, better ventilation could be occurred in a street with various building heights. Moreover, the $\mathrm{H} / \mathrm{W}$ ratio affects the quantity of solar energy obtained by street surfaces (facades, roofs and ground). Decrease of the H/W ratio increases solar access in the street. Street orientation hardly influences the amount of solar radiation of the canyon; it causes differences in the distribution of the total radiation over the different street surfaces. Street orientation significantly influences the diurnal and seasonal pattern of irradiation of the street surfaces and it is more affective on the vertical surfaces of the street.

Therefore, in order to provide a pleasant microclimate in urban areas, designing urban streets in a way which brings about appropriate airflow and utilize solar access is vital and essential. This could affect global climate and energy consumption of buildings.

\section{REFERENCES}

[1] M. Srivanit and H. Kazunori, "The Influence of Urban Morphology Indicators on Summer Diurnal Range of Urban Climate in Bangkok Metropolitan Area, Thailand," International Journal of Civil \& Environmental Engineering, vol. 11, no. 5, pp: 34-46, 2011

[2] C. S. B. Grimmond, M. Roth, T. R. Oke, Y. C. Au, M. Best, R. Betts, G. Carmichael, H. Cleugh, W. Dabberdt, R. Emmanuel, E. Freitas, K. Fortuniak, S. Hanna, P. Klein, L. S. Kalkstein, C. H. Liu, A. Nickson, D. Pearlmutter, D. Sailor, and J. Voogt, "Climate and More Sustainable Cities: Climate Information for Improved Planning and Management of Cities (Producers/Capabilities Perspective)," Procedia Environmental Sciences, vol. 1, pp.247-274, 2010.

[3] L. M. Huang, H. T. Li, and D. H. Zhu, "A fieldwork study on the diurnal changes of urban microclimate in four types of ground cover and urban heat island of Nanjing, China," Buildings and environment, vol. 43, pp. 7-17, 2008.

[4] TR. Oke, "Street design and urban canopy layer climate," Energy and Buildings, vol.11, pp.103-113, 1988.

[5] F. Bourbia and F. Boucheriba, "Impact of street design on urban microclimate for semi arid climate (Constantine)," Renewable Energy, vol.35, pp. 343-347, 2010.

[6] J. Voogt, "Urban Heat Island," Encyclopedia of Global Environmental Change, vol. 3, pp. 660-666, 2002.

[7] J. Arnfield, "Street design and urban canyon solar access," Energy and Buildings, vol.14, pp.117-31, 1990.

[8] L. Shashua-Bara and M. E. Hoffman, "Geometry and orientation aspects in passive cooling of canyon streets with trees," Energy and Buildings, vol. 35, pp. 61-68, 2003.

[9] K. Syrios and G. R. Hunt, "Passive air exchanges between building and urban canyon via openings in a single façade," International Journal of Heat and Fluid Flow, vol.29, pp. 364-373, 2008.

[10] K. Ahmad, M. Khare, and K. K. "Chaudhry, Wind tunnel simulation studies on dispersion at urban street canyons and intersections-a review," Journal of Wind Engineering and Industrial Aerodynamics, vol. 93, pp. 697-717, 2005.

[11] F. Ali-Toudert and H. Mayer, "Numerical study on the effects of aspect ratio and orientation of an urban street canyon on outdoor thermal comfort in hot and dry climate," Buildings and Environment, vol. 41, pp. 94-108. 2006.

[12] P. E. Todhunter, "Microclimatic Variations Attributable to Urban Canyon Asymmetry and Orientation," Physics and Geography, vol. 11, pp.131-141, 1990.

[13] A. Yoshida, K. Tominaga, and S. Watani, "Field measurements on energy balance of an urban canyon in the summer season," Energy and Buildings, vol. 15-16, pp. 417-423, 1990/91.
[14] J. Arnfield and G. Mills, "An analysis of the circulation characteristics and energy budget of a dry, asymmetric, east-west urban canyon. II. Energy budget," International Journal of Climatology, vol. 14, pp.239-261, 1994.

[15] Y. Nakamura and T. Oke, "Wind, temperature and stability conditions in an east-west oriented urban canyon," Atmospheric Environment, vol. 22, pp. 2691-2700, 1988

[16] D. N. Asimakopoulos, V. D. Assimakopoulos, N. Chrisomallidou, N. Klitsikas, D. Mangold, P. Michel, M. Santamouris, and A. Tsangrassoulis, Energy and climate in the urban built environment, $1^{\text {st }}$ edition, James \& James. London: UK, 2001.

[17] D. Hawkes and W. Foster, Energy efficient buildings, Architecture, Engineering, and Environment, $1^{\text {st }}$ edition, W. W. Norton and company, New York: USA, 2002.

[18] L. Yang and Y. Li, "Thermal conditions and ventilation in an ideal city model of Hong Kong," Energy and Buildings, vol. 43, no. 5, pp.1139-1148, 2011.

[19] RA. Memon and DYC. Leung, "Impacts of environmental factors on urban heating," Journal of Environmental Sciences-China, vol. 22, no. 12, pp.1903-1909, 2010.

[20] A. Al-Sallal and L. Al-Rais, "Outdoor airflow analysis and potential for passive cooling in the modern urban context of Dubai," Renewable Energy, vol.38, pp. 40-49, 2012.

[21] R. Thomas, and M. Fordham (eds.), Sustainable Urban Design: An environmental approach. London and New York: E \& FN Spon, 2003.

[22] A. Okeil, "A holistic approach to energy efficient building forms," Energy and Buildings, vol. 42, pp. 1437-1444, 2010.

[23] M. Santamouris, N. Papanikolaou, I. Koronakis, I. Livada, and D. Asimakopoulos, "Thermal and air flow characteristics in a deep pedestrian canyon under hot weather conditions," Atmospheric Environment, vol. 33, pp.4503-4521, 1999.

[24] A. Robins and R. Macdonald, "Review of Flow and Dispersion in the Vicinity of Buildings," Atmospheric Dispersion Modeling Liaison Committee Annual Report, 1999.

[25] M. Hussain and B. E. Lee, "An investigation of wind forces on the 3D roughness elements in a simulated atmospheric boundary layer flow," Part II- Flow over large arrays of identical roughness elements and the effect of frontal and side aspect ratio variations. Department of Building Sciences. University of Sheffield: UK, 1980.

[26] R. P. J. Hosker, "Flow around isolated structures and building clusters: a review," ASHRAE Transactions, vol. 91, pp. 1671-1692, 1985.

[27] E. Johansson, "Influence of urban geometry on outdoor thermal comfort in a hot dry climate: a study in Fez, Morocco," Building and Environment, vol. 41, pp. 1326_1338, 2006.

[28] R. Priyadarsini and N. Wong, "Parametric studies on urban geometry, airflow and temperature," International journal on architectural science, vol. 6, no. 3, pp. 114-132, 2005.

[29] A. T. Chan, E. S. P. So, and S. C. Samad, "Strategic guidelines for street canyon geometry to achieve sustainable street air quality," Atmospheric Environment, vol.35, pp. 5681-5691, 2001.

[30] G. Golany, "Urban design morphology and thermal performance," Atmospheric Environment, vol. 30, no. 3, pp. 45-65, 1996.

[31] M. M. E. van Escha, R. H. J. Loomana, and G. J. de Bruin-Hordijka, "The effects of urban and building design parameters on solar access to the urban canyon and the potential for direct passive solar heating strategies," Energy and Buildings, vol. 47, pp.189-200, 2012.

[32] F. Ali-Toudert and H. Mayer, "Planning-oriented assessment of street thermal comfort in arid regions," presented at the 21th Conference on Passive and Low Energy Architecture. Eindhoven, Netherlands, 19 - 22 September 2004

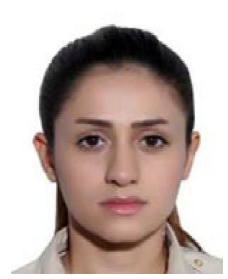

Nastaran Shishegar was born in Ahvaz, Iran, on December 31, 1985. She received Master of Architecture (housing) in 2011 and Bachelor of Architecture in 2007 from Iran University of Science and Technology (IUST) in Tehran, Iran with firs class honor.

She is a researcher. She has conducted some studies in different field such as sustainable design, environmental performance of design, passive solar architecture, green roofs and mitigation of urban heat island effect. She published an article on the impacts of green roofs on energy and environmental performance of buildings on the 12th international conference on clean energy. Nowadays she is writhing tow other papers about the impacts of green spaces on mitigating Urban Heat Island effect and also the impacts of design parameters on outdoor and indoor solar access. 